\title{
Interpretação histórica e transformação científica: a tarefa hermenêutica de uma teoria crítica da epidemiologia
}

\author{
Historical interpretation and scientific transformation: the hermeneutical task of \\ a critical theory of epidemiology
}

\author{
José Ricardo de C. M. Ayres*
}

\begin{abstract}
AYRES, J.R. de C.M. Interpretação histórica e transformação científica: a tarefa hermenêutica de uma teoria crítica da epidemiologia. Rev. Saúde Pública, 28: 311-9, 1994. São discutidas as contribuições trazidas pela abordagem histórica ao debate epistemológico da epidemiologia. Buscando-se na teoria do agir comunicativo, de Habermas, e na filosofia hermenêutica de Gadamer, enriquecimentos para uma compreensão práxica das ciências, procura-se explorar o sentido em que a perspectiva histórica redimensiona as questões epistemológicas básicas da epidemiologia. A argumentação aponta para a maior fecundidade desta aproximação, em contraste com as aproximaçōes estritamente lógico-formais, na apreensão dos impasses teóricos com que se defronta a epidemiologia na busca de seus axiomas científicos. Destaca-se, em particular, o potencial emancipador do resgate da historicidade no âmbito da própria atividade epistemológica.
\end{abstract}

Descritores: Epidemiologia. História. Filosofia. Medicina social.

\section{Introdução}

É marcante a percepção de dificuldades epistemológicas no campo da epidemiologia entre os profissionais que, cientistas ou não, trabalham com esse saber. A epidemiologia é uma ciência ou um método? Seu objeto é a distribuição ou a determinação dos fenômenos coletivos de saúde? O fenômeno epidemiológico é o evento relativo à saúde ou o padrão de ocorrência desse evento? Que tipo de determinismo é adequado à explicação epidemiológica? A inferência epidemiológica deve privilegiar a via indutivo-verificacionista ou a dedutivo refutacionista? Até que ponto a direcionalidade do estudo epidemiológico é determinado por seu objeto de investigação? Questões dessa natureza estão cotidianamente permeando as práticas epidemiológicas.

Ciência relativamente jovem, de caráter aplicado e situada numa área de fronteira entre campos

Centro de Saúde Escola Samuel B. Pessoa (C.S.Escola do Butantã), Departamento de Medicina Preventiva da Faculdade de Medicina da Universidade de São Paulo São Paulo, SP - Brasil

Separatas/Reprints: J.R. de C.M. Ayres - Av. Dr. Vital Brasil, 1490 - Butantã - 05503-000 - São Paulo, SP - Brasil

Edição subvencionada pela FAPESP. Processo 94/0500-0 científicos muito distintos em termos metodológicos, não têm sido pequenas as dificuldades que a epidemiologia tem enfrentado para consolidar axiomas que garantam, de forma simultânea, a validade, a aplicabilidade e a especificidade de seu discurso científico?.

O predomínio de uma atitude filosófica positivista nas discussões epistemológicas que têm sido travadas na comunidade epidemiológica, em especial nos países de língua inglesa, têm estabelecido, por outro lado, limites estreitos para a abordagem do problema. Em sua restrição ideológica e filosófica às determinações "internas" ao conhecimento ${ }^{1}$, o positivismo epistemológico não permite à reflexão metacientífica da epidemiologia chegar ao plano em que parecem estar radicadas suas principais aporia.

Sob os pressupostos e axiomas positivistas, as ciências, de um modo geral, diante de dificuldades empíricas ou conceituais em relação à sua consistência teórica, tendem a apreender e solucionar esses impasses epistemológicos num plano eminentemente formal. Contam, para isso, com o exemplo do mais influente modelo de conhecimento abstrato já conhecido por elas, a matemática. Com efeito, tão fundamental no desenvolvimento das ciências quanto o seu extensivo recurso a instrumentos matemáticos ${ }^{38}$, tem sido a reprodução, nas estruturas particulares dessas ciências, dos processos de abstração pelo qual esses instrumentos são construídos ${ }^{13}$. 
Quando encontra obstáculos às suas necessidades teóricas, a matemática recorre a dois expedientes metodológicos básicos, compatíveis com o caráter formal de seus procedimentos e o conteúdo abstrato de seus constructos: ampliação do seu sistema de objetos conceituais e/ou restrição do sistema de operações relativas a tais objetos ${ }^{16}$. Foi assim, por exemplo, quando a insuficiência das grandezas ditas naturais, frente às exigências de algumas operações algébricas, levou à formulação do conceito de números complexos; ou quando a teoria dos conjuntos reduziu a um número determinado de possibilidades suas operações, para garantir a consistência lógica dessa teoria.

É claro que, no caso das ciências de conteúdo mais imediatamente empírico, tais procedimentos não terão o mesmo alcance. Sua utilização nessas ciências presta-se, em geral, não à transformação de seu alcance teórico mas, tão somente, ao aumento, do grau de positividade dos seus enunciados. Os resultados desses ajustes não atingirão o conteúdo de conceitos e métodos, como acontece na matemática, mas apenas as condiçôes de validade das inferências dessas ciências. Ocorre que isto é freqüentemente considerado suficiente.

A epidemiologia não foge à regra. Os impasses decorrentes do complexo contexto de definição de seus axiomas têm sido examinados, quase exclusivamente, no campo da consistência formal da construção científica. São conhecidos os prejuízos que se pode esperar dessa unilateralidade epistêmi$\mathrm{ca}^{28}$. Não é de estranhar, por exemplo, que uma das mais sólidas e ousadas discussões surgidas na literatura norte-americana recente, numa evidente metonímia matemática, circunscreva suas formulações a um duplo ajuste objetivo-operatório. Em seu "Theoretical Epidemiology", Miettinen27 propõe adensar a identidade científica da epidemiologia a partir da consolidação de dois movimentos, os quais, segundo esse autor, já estariam ocorrendo na prática epidemiológica concreta:

a) expansão do sistema de objetos: não apenas fenômenos de saúde e doença, mas também "estados e eventos não médicos no homem" e "objetos não humanos igualmente";

b) restrição do sistema operatório: não mais o estudo da distribuição populacional dos fenômenos da saúde e da doença e seus determinantes, mas apenas o "estudo da ocorrência" desses fenômenos.

Ainda que se partilhe do diagnóstico de Miettinen a respeito das tendências recentes das práticas de investigação na epidemiologia, caberá questionar a proposição que dele o autor faz derivar. Será possível ignorar que a equivalência entre "objeto humano" e "objeto não-humano" tem raízes e implicações práticas que desautorizam tratá-la como uma simples expansão de catcgorias abstratas de raciocínio? Será possível aceitar que a restrição operatória das investigações epidemiológicas seja uma livre opção dos epidemiologistas, uma escolha entre uma pretensão inicial, que teria se mostrado demasiado "romântica" para efetivar-se, e outra, menos ambiciosa porém capaz de realizar a tão almejada consolidação do estatuto científico da epidemiologia? Em caso positivo estar-se-á, sem dúvida, colocando a epidemiologia numa situação mais cômoda para solucionar os impasses listados ao início do texto, ainda que a um preço talvez inafiançável. Se, ao contrário, as respostas forem negativas, então somam-se às questões lá enumeradas outras, relativas agora à metaciência epidemiológica, à sua reflexão epistemológica.

São essas questões metacientíficas que justificam o presente ensaio, cujo objetivo central é mapear algumas possibilidades de superação do horizonte estritamente formal da reflexão epistemológica na epidemiologia. Proceder-se-á à exploração de desenvolvimentos teóricos que favoreçam uma aproximação epistemológica que não se restrinja ao plano formal dos impasses epidemiológicos, mas que permita interpretá-los quanto à sua transcendência histórica.

\section{Epidemiologia e práxis}

Subjaz à proposta miettineniana de "endurecimento" da ciência epidemiológica, assim como a outras discussões metaepidemiológicas de corte positivista, uma concepção a respeito da verdade possível e necessária na epidemiologia que coloca a si própria acima de questão ${ }^{3}$. Em nenhum momento introduz-se na discussão a questão do sentido histórico dessas verdades e dos métodos a ela associados. Postula-se apenas o problema do rigor lógico dos constructos no âmbito de uma certa relação já dada entre verdade, método e objeto, tomada como externa ao processo científico em si mesmo.

Outras formas de autocompreensão da razão e de suas ciências buscam, ao contrário, fazer de uma reflexão ética, fundada em contextos de práticas historicamente circunscritos, a perspectiva privilegiada para apreender a razão humana $e$ as ciências. A "filosofia da práxis" representa, sem dúvida, um dos mais expressivos desenvolvimentos realizados nessa direção pela racionalidade ocidental moderna ${ }^{19}$.

Ao conceber-se como constituinte da práxis humana, a razão entende a si própria como "instru- 
mento" do trabalho social, e nessa condição se baseia a positividade de sua potente auto-crítica. Isto é, a partir de uma dialética do trabalho ${ }^{21}$, a razão constrói um auto-entendimento que abdica de qualquer aspiração universal e absoluta. Ela assume a si mesma como uma experiência de sujeitos datados e localizados, identificados por referência às formas particulares como estes produzem, pela razão e com a razão, modos socialmente organizados de satisfazer e reproduzir necessidades materiais e imateriais. $O$ conceito filosófico, ou metaconceito, de práxis incorpora à reflexão epistemológica, portanto, a consciência de pertença da ciência a sujeitos históricos, caracterizados por valores e práticas dialeticamente articulados às condições materiais de sua existência. Em consequiência, incorpora substantivamente à sua autocompreensão a relação com esses valores, práticas e condições materiais ${ }^{23}$.

Entender a epidemiologia como práxis redimensiona radicalmente a natureza e o alcance dos problemas de sua axiomatização. $O$ processo que Miettinen trata como um fato dado, que só cabe à epidemiologia radicalizar e controlar em termos formais, torna-se o fulcro da reflexão. Os impasses vividos pela epidemiologia não se reduzirão a problemas a serem resolvidos. Eles configuram um devir histórico; constituem o substrato de uma ilimitada necessidade de autocompreensão e contínua (re)construção do conhecimento ${ }^{30}$.

Não cabe, nos propósitos do presente ensaio, examinar a constituição histórica da práxis epidemiológica, de resto, já explorada em outro trabalho ${ }^{4}$. No entanto, uma breve síntese desse processo será aqui útil em dois sentidos. Em primeiro lugar, ela deixará mais claro o "giro epistemológico" que o paradigma da práxis imprime à discussão metaepidemiológica. Em segundo lugar ela permitirá situar melhor alguns dos aspectos teóricos que se deseja discutir. É preciso éstar atento, entretanto, para as reduções em que sémpre incorrem as sínteses de processos da amplitude e complexidade do que aqui se abordará. Fique então o alerta, não como, justificativa de qualquer insuficiência do texto, naturalmente, mas para resguardar o leitor de eventuais prejuízos.

É sabido que as primeiras práticas sanitárias e os primeiros saberes de natureza epidemiológica estão relacionados ao reconhecimento, em escala populacional, das desigualdades no adoecer humano, tornando-se, no fim do século XVIII e início do XIX, potentes instrumentos da emancipação da ordem social capitalista. Sabe-se, ainda, que modificações importantes aconteceram nesse campo quando esta nova ordem foi consolidada. A trajetória que conduz, dos primeiros esboços de um saber objetivo sobre a relação da saúde com o "espaço público da sociedade burguesa" 18 , à conformação da epidemiologia, nos moldes de uma ciência moderna, é a expressão do duplo processo de apreensão e negação de uma esfera propriamente pública de determinação do processo saúde-doença.

A preocupação com a relação entre a saúde e o modo como está socialmente organizado o espaço público, isto é, os espaços físicos, institucionais e culturais de interação dos indivíduos entre si e com o seu ambiente, aglutinou na aurora da Idade Moderna, uma ampla gama de sujeitos sociais. A partir de projetos políticos diversos, vinculados às novas formas de divisão social do trabalho, o espaço público da saúde conformou uma esfera de necessidades comuns a esses sujeitos, somando-se às aspirações que reclamavam a construção de uma nova ordem social. Foi em relação com essas necessidades que, no seio da higiene, plasmou-se o saber epidemiológico.

Quando se tratava já de consolidar e reproduzir a nova ordem social, a preocupação com a dimensão pública da saúde experimentou um "apaziguamento" de certo modo inevitável. Ultrapassado o período revolucionário, o projeto politicamente hegemônico imprime à problemática do espaço público da saúde limites mais restritos. Como contrapartida, o saber epidemiológico, até então difusamente dimanado da higiene pública, torna-se um campo autônomo de conhecimento, incorporandose ao processo técnico-científico hegemônico através de uma evidente restrição de suas pretensões explicativas e de suas esferas de aplicação. Essa "redução" torna-se mais clara quando se examina de perto o processo de "formalização científica" 8,12 da epidemiologia.

O saber epidemiológico configurou-se como uma ciência quando, em meados do século XIX, passou a ocupar-se do espaço público da saúde até então tratado pela higiene como uma esfera substantiva de determinação - por intermédio da apreensão de fatores de interdição ou de facilitação da determinação fisiopatológica dos diversos agravos à saúde. Isso foi possível graças ao conceito de um "meio externo"7, que permitiu à ciência epidemiológica relacionar causalmente os fenômenos orgânicos e extra-orgânicos da saúde, subordinando a apreensão do segundo ao primeiro através do privilégio da fisiopatologia na eleição e validação de hipóteses explicativas ${ }^{35}$. A teoria do contágio veio substituir, então, a transcendência socionatural dos miasmas na explicação "epidemio-lógica". A ênfase do conhecimento e intervenção relativos aos fenômenos da saúde pública passou, a dirigir-se à imanência da mecânica externo-interno do evento patológico, à dimensão individual e natural do adoecimento. 
Em meados do século XX observa-se uma nova inflexão. Aqui, consubstancialmente ao aprofundamento das relações sociais capitalistas $\mathrm{e}$ ao tecnicismo que passa a dominar o mundo do pós-guerra, o causalismo biologicista é superado pela associação probabilística de natureza cau$\mathrm{sal}$, traduzida no conceito estritamente instrumental de risco ${ }^{2}$. O movimento de redução, acima apontado, torna-se aqui ainda mais eficaz, porque prescinde agora da própria explicação da "mecânica" que relaciona orgânico e extraorgânico. À epidemiologia bastará conhecer o sentido estatístico de interdição ou facilitação da associação supostamente causal. O possível é identificado ao provável, o amostral ao populacional e este ao individual, numa manobra lógica triplamente problemática ${ }^{34}$.

O "paradigma" 24 do risco abriu série de novas e relevantes possibilidades para o conhecimento epidemiológico e para as suas relações com os saberes e práticas da clínica, nucleares no campo da saúde ${ }^{26}$. Ao fazê-lo, no entanto, a epidemiologia aprofundou proporcionalmente o sentido redutor de sua leitura sobre o espaço público da saúde. Se é verdade que hoje não existe saber em saúde que não esteja direta ou indiretamente amparado em conhecimentos epidemiológicos, é também um fato que não há conhecimento epidemiológico expressivo fora do campo de indagações de base clínica e, especialmente, não há inferência epidemiológica legitimável fora da consistência com os critérios de validação estabelecidos para as ciências que apreendem a saúde no plano da individualidade orgânica. A tal ponto chegou essa subordinação, que epidemiologistas de perfis os mais diversos vêem na epidemiologia não uma ciência, mas apenas um método de investigação ${ }^{25,27}$.

Eis aqui o que parece ser o núcleo dos impasses experimentados pela epidemiologia contemporânea: constituir-se de tal forma a ver desvanecer-se, na mesma medida de sua penetração social $e$ aprimoramento técnico, a sua identidade científica e os seus compromissos sócio-históricos originais.

A preocupação com a dimensão propriamente pública da saúde, não no sentido de uma condição que atinge coleções de indivíduos, mas no de uma experiência vital de comunidade de destinos, é ela ainda um valor efetivamente operante nas sociedades contemporâneas ? Que relação guarda a positividade ou negatividade dessa preocupação com as finalidades que movem os sujeitos da investigação epidemiológica? Como se articulam os elementos empíricos e metodológicos da epidemiologia com essas finalidades? Quais são as possibilidades efetivas de condução do debate sobre as finalidades da investigação ao território da validação científica? Quais são os sujeitos desse virtual debate? Essa é a forma como se reconstrói aqui a problemática epidemiológica à luz de uma compreensão práxica e, com ela, os seus desafios metacientíficos.

Um exame criterioso dessas indagações chamará a atenção, entretanto, para um aspecto filosófico muito importante. Trata-se do fato de que suas respostas ultrapassam as possibilidades do paradigma que as engendrou. Em outras palavras, se o paradigma da práxis permite um outro olhar sobre o problema da epidemiologia, se denuncia determinações sócio-históricas onde parecia só haver questões lógico-formais, quando se trata de examinar a "intimidade" dessas determinações a dialética do trabalho encontra limites evidentes. A menos que se adote concepções metafísicas ou naturalistas de uma determinação imediata entre as necessidades humanas de produção-consumo e os meios de sua satisfação, do que não se trata, não parece possível responder às questões acima nos marcos restritos da dialética do trabalho, sem que a reflexão seja, necessariamente, conduzida a tautologias que não interessam a esta reflexão. Assim como as epistemologias clássicas, apoiadas na concepção kantiana de um sujeito universal do conhecimento, apreendem a "atividade da razão" por meio da "razão em atividade", de modo semelhante (apenas na perspectiva lógica, naturalmente), tratar-se-ia de entender "a razão que produz" pela "produção da razão". Em nada se faria avançar as necessidades de fundamentação aqui reclamadas.

Construções filosóficas de modo algum incompativeis com o metaconceito de práxis, mas que deslocam de modo significativo seu horizonte especulativo tradicional ${ }^{5}$, parecem promissoras no sentido de fazer avançar a reflexão epistemológica para além dos territórios onde se detém a dialética do trabalho. Trata-se de constructos plasmados numa dialética das interações ${ }^{21}$.

A dialética do trabalho "pede" aqui a dialética das interações. Sem esta, um tratamento práxico da ciência tenderá a oscilar entre duas alternativas igualmente insatisfatórias: ou se toma a ciência como uma prática mecanicamente determinada por finalidades produtivas ou, inversamente, como uma racionalidade que estabelece arbitrariamente tais finalidades. Nada mais artificial. Uma atitude mais fecunda é apreender a prática científica como a construção (aparentemente) una de contribuições (necessariamente) múltiplas de diversos sujeitos portadores de projetos e poderes diversos. A ciência precisa ser investigada, nesse sentido, na condição de um campo de intensas e complexas relações intersubjetivas. Para esse propósito, um denso constructo filosófico contemporâneo parece 
oferecer subsídios fundamentais: a teoria do agir comunicativo, de Habermas ${ }^{20}$. Uma síntese das potenciais contribuições dessa teoria para uma epistemologia não formalista é o que se procurará discutir a seguir.

\section{Ação comunicativa e validação científica}

Habermas $^{20}$ entende a busca do esclarecimento, processo simultâneo de conhecimento do mundo e auto-objetivação humana através da razão, como uma grande construção coletiva, um diálogo, sempre em marcha, entre discursos diversos sobre a realidade. Esses discursos são resultantes da interação entre os diferentes horizontes interpretativos abertos pelas experiências concretamente vividas pelos sujeitos humanos, e segundo os distintos poderes de que desfrutam na organização social da vida.

Sob a perspectiva habermasiana, as ciências, esses discursos que perscrutam o mundo aspirando expressar suas verdades, estão fundadas em certezas provisórias, linguiisticamente construídas. Para Habermas, a verdade dos enunciados científicos não decorre de uma aptidão universal do sujeito do conhecimento, tampouco da percepção de condições absolutamente imanentes dos objetos do conhecimento. Nas formas concretas de socialidade engendradas na era do capitalismo financeiro e da cultura de massas, a verdade assume a forma de um discurso comunicativamente operante.

Segundo esse princípio, a construção da verdade na ciência, como em qualquer discurso racional na contemporaneidade, dá-se com base em três níveis de legitimação: a) na proposição de enunciados coerentes com a realidade de contextos intersubjetivamente compartilhados; b) nos potenciais desses enunciados para a implementação de condições favoráveis ao bom êxito dos projetos sociais definidos nos contextos em que se conformam esses discursos ("formas não antecipáveis de uma vida não fracassada"20); e c) na sua capacidade de estabelecer efetiva comunicação, isto é, de implementar e enriquecer a autenticidade dos conteúdos compartilhados intersubjetivamente.

À crença numa verdade universal, absoluta nos primeiros positivismos e relativa nos neopositivismos $^{1}$, Habermas contrapõe, portanto, uma concepção consensual da verdade. A validade do conhecimento objetivo repousa na intersubjetividade que funda toda construção racional. A pretensão de verdade de um discurso é, assim, vinculado à sua "valorização" entre os diversos discursos em interação nos três níveis acima apontados: a) na sua capacidade de expressar certezas compartilháveis, isto é, na sua positividade proposicional; b) na possibilidade de instruir ações eficazes no âmbito dos projetos sociais relativos a tais realidades, isto é, na sua adequação normativa; e c) no êxito em estabelecer efetiva intersubjetividade entre os diversos sujeitos envolvidos nessas açōes, isto é, na sua autenticidade.

Com base nessas proposições, e dada a arquitetura conceitual da epidemiologia contemporânea, é possível definir três níveis interligados de interrogação a respeito da construção/legitimação da verdade nessa ciência, eixos em torno dos quais gravitam as interações intersubjetivas de sua prática científica:

- Em que plano semântico da experiência humana dos processos saúde/doença o conceito epidemiológico de risco reivindica seu estatuto de verdade? Em qual sistema de signos/ significados os eventos probabilísticos com que trabalha a epidemiologia têm fundada sua positividade? Que realidade, enfim, é visada pelas pretensões de validade proposicional da linguagem epidemiológica?

- Que tipo de eficácia visam esses enunciados, ou seja, que valores positivos de saúde e seus correlatos projetos normativos, explícitos ou não, subjazem à concepção das diversas modalidades de risco epidemiológico?

- Em que esferas de comunicação estão apoiados esses conceitos, isto é, entre que sujeitos sociais, e a respeito de quais necessidades humanas, as diversas modalidades de risco realizam autêntica interlocução?

A particularização desses três níveis de desdobramento de uma aplicação epistemológica da referência habermasiana, assim como sua condução a um nível de concretude mínimo para se vislumbrar o essencial da problemática epidemiológica contemporânea, chama a atenção, por sua vez, para um outro aspecto fundamental para a reflexão metaepidemiológica. Trata-se do significado dos constructos conceituais da epidemiologia em termos do conteúdo das experiências intersubjetivas a que remetem.

De modo similar ao observado com a dialética do trabalho, é possível perceber, pela natureza das questões acima, um "excesso" do conteúdo das respostas reclamadas por referência à perspectiva que as suscita. Com efeito, o discurso epidemiológico, enquanto estrutura lingüística, não esgota o significado das experiências que representa. Estão envolvidos no contcúdo das três esferas de questões acima não apenas uma dimensão epistemológica e ética, em sentido estrito, mas também uma dimensão estética, na acepção kantiana de um conjunto de intuições em que se funda a experiência 
sensível não metabolizada pelo pensamento, não organizada em termos do entendimento.

Entre as suas inúmeras heranças à filosofia contemporânea, Kant deixou-nos a convicção de que não é possível pensar numa separação radical, muito menos na coincidência, entre conhecimento objetivo e experiência estética do mundo ${ }^{10}$. Toda objetivação racional será sempre a apreensão parcial e estática de experiências cuja totalidade escapa à sua limitada perspectiva, mas à qual estará necessariamente vinculada, posto fazer parte dela. A dimensão estética será sempre, portanto, essa espécie de "duplo" da dimensão epistemológica das ciências, uma parte inexorável de sua realidade, porém intangível nos termos parciais em que os conceitos representam-na.

De fato, como conceber que experiências como "sistema de signos/significados", "valores positivos de saúde" ou "necessidades humanas" possam ser inteiramente recobertas por qualquer discurso objetivo? Como imaginar que a linguagem epidemiológica possa traduzir imediatamente a experiência vivida do adoecer coletivo? Impossível. A negação do "Mal" ocultada sob a positividade dos conceitos, a gestão simbólica da doença no fundo de cada projeto normativo, a construção sociocultural da identidade dos sujeitos, aspectos profundamente implicados no conceito etnologicamente mais nuclear da epidemiologia, o de "epidemia", são exemplos da complexidade estética desse campo científico ${ }^{37}$ e constituem dimensões tão importantes para a compreensão da constituição da epidemiologia quanto a técnica de inferência matemática, a fisiopatologia, a sociologia do espaço público, entre outras.

Pode-se, então, depreender dessa argumentação que o mais substantivamente particular nas interações que medeiam a conscrução de uma ciência como a epidemiologia, o núcleo mesmo de sua historicidade, encontra-se nessas experiências ao mesmo tempo reveladas e ocultadas pelos seus constructos conceituais. Conseqüentemente, a reflexão epistemológica terá muito a expandir o seu potencial elucidativo caso esse "excesso" da experiência na linguagem epidemiológica seja consciente e ativamente explorado. Um projeto epistemológico consistente não pode desconsiderar, assim, uma terceira região da dialética da razão, a dialética das representações ${ }^{21}$, ou seja, não pode se furtar ao trabalho interpretativo que se impõe à compreensão da intersubjetividade realizada pela ciência.

\section{A tarefa hermenêutica da epistemologia}

A hermenêutica, que podemos designar genericamente como " $\mathrm{a}$ arte e a ciência da interpre- tação" 33 , cabe a tarefa fundamental de uma epistemologia não restrita à dimensão formal da construção do conhecimento.

O termo "hermenêutica", etimologicamente ligado a Hermes, deus que traduzia as mensagens do Olimpo para os mortais, tem designado práticas e referenciais teóricos significativamente distintos, mas que têm em comum o sentido lato de "decodificação". É possível agrupá-las em pelo menos três categorias que em muitos aspectos se confundem e interpenetram ${ }^{6}$ :

a) Teoria hermenêutica - associada originalmente aos movimentos do Renascimento e da Reforma, trata-se da sistematização de uma série de princípios e procedimentos para a interpretação de obras não contemporâneas, no caso, as Sagradas Escrituras e os textos da Antiguiidade Clássica. Mais tarde, no século XIX, a escola historicista alemã recorreria ao delineamento de uma teoria hermenêutica com o intuito de validar um conhecimento próprio às ciências humanas, ou "ciências do espírito", em contraste com o empirismo das "ciências naturais"11.

b) Filosofia hermenêutica - trata-se do desenvolvimento, a partir especialmente da filosofia de Heidegger, de uma reflexão metadiscursiva que funda a compreensão de realidades e obras humanas na sua lingüisticidade. Lança mão de uma série de procedimentos analíticos e de conceitos da teoria hermenêutica, mas rompe radicalmente com sua aspiração objetivista ${ }^{15}$.

c) Hermenêutica crítica - ou crítica dialéticohermenêutica, designa proposições que atribuem à hermenêutica uma tarefa compreensiva fundamental, mas que enxergam limites na dimensão lingüística para fundamentar uma interpretação efetivamente crítica e emancipadora dos fatos humanos ${ }^{17}$.

As categorias acima discriminadas, especialmente as duas últimas, não são, como já indicado, estanques e excludentes entre si. Para uma metacrítica da ciência os pontos de convergência entre hermenêutica filosófica e crítica hermenêutica são, aliás, mais expressivos do que os de divergência. $\mathrm{O}$ que suas proposições têm de mais essencial é caracterizar-se como uma profunda rejeição da tecnocracia, da redução instrumental da racionalidade contemporânea, opondo a natureza integradora do sentido ético e político do conhecimento ao caráter fragmentário e auto-regulado a ele impresso pelo tecnicismo ${ }^{36}$. Em suma, a mais marcante contribuição de ambas, e alvo do seu principal interesse para os objetivos do presente trabalho, é seu compromisso com o resgate crítico da historicidade do conhecimento. 
A diferença epistemologica básica entre a filosofia hermenêutica e a hermenêutica crítica reside na esfera onde suas construções metaconceituais fundam a historicidade do conhecimento, se na sua própria lingüisticidade, como é característico da ontolingüística heideggeriana, a que se filia Gadamer, ou se em esferas de experiência ainda mais abrangentes em relação à linguagem, marca da herança frankfurtiana de Habermas ${ }^{22,29}$.

A posição habermasiana tem como principal preocupação a relação entre valor e conhecimento. Para isso toma a linguagem na perspectiva da ação dos sujeitos, das suas "vontades", condição primária de possibilidade da história. De acordo com Habermas ${ }^{20}$, a estruturação lingüística da experiência já carreia consigo, em certa medida, determinados valores e competências discursivas, isto é, assimetrias de poder entre os diversos sujeitos que interagem pela linguagem na conformação dos discursos. Uma hermenêutica que não tematize a própria linguagem, isto é, que não se distancie dialeticamente dela para compreendê-la, terá, segundo Habermas ${ }^{20}$, seu horizonte interpretativo pré-determinado por essas assimetrias de poder inscritas na linguagem. Uma atitude efetivamente emancipadora exige, portanto, que a razão busque compreender, na dialética de suas determinações intralingüísticas e extralinguísticas, a aptidão das ciências para representar legitimamente as diversas experiências do mundo. Assim, instruída pela idéia reguladora de um diálogo livre de dominação, pedra angular de sua filosofia, Habermas postula que uma hermenêutica crítica deve buscar identificar os liames lingüisticos que caracterizam obstáculos à livre expressão discursiva dos sujeitos.

Aplicado à situação da epidemiologia, o raciocínio de Habermas permite assumir, por exemplo, que o abandono da conceituação miasmática do fenômeno coletivo de saúde em favor de uma concepção contagionista terá deixado para trás bem mais que uma simples alternativa explicativa. $\mathrm{Na}$ verdade, houve aí um redimensionamento na validação proposicional, normativa e expressiva das "vontades de saúde" socialmente plasmadas e sancionadas. Estas, ao se rearticularem em novos conceitos, foram transmitidas às geraçōes seguintes como um outro universo discursivo sobre saúde. Depois de Snow, o que quer que significasse, em termos de vontade de saúde, pensar e interagir "miasmaticamente" foi subsumido em uma nova ordem de possibilidades pelo conceito de contágio, até o limite virtual da supressão total. O terreno de possibilidades para as vontades de saúde, constituídas a partir do conceito de contágio, experimenta, por sua vez, novas transformações quando se constrói uma tradução bacteriológica desse contágio, e assim sucessivamente até às associações probabilísticas atuais.

O ideal de construção da livre manifestação de vontades no contexto sanitário contemporâneo passa, a partir dessa perspectiva, por uma hermenêutica profunda do discurso epidemiológico, não para resgatar, obviamente, a totalidade das vontades de saúde "interditadas" na trajetória da construção do discurso epidemiológico, mas sim para identificar nos movimentos históricos dessa interdição o seu sentido opressor, e superá-lo.

É na obra de Gadamer ${ }^{15}$, por paradoxal que possa parecer, que serão encontradas algumas das mais valiosas contribuições para a realização dessa hermenêutica profunda, à qual conduz o raciocínio acima. É que ao rejeitar a extrapolação do plano lingüístico na interpretação (ainda que, na prática, não realize integralmente esse projeto ${ }^{31}$ ), Gadamer se vê diante da necessidade de desenvolver uma espécie de "analítica" do sentido, uma profunda discussão das relações intrínsecas entre ethos e linguagem.

O leitmotiv da obra de Gadamer $^{15}$ é a superação da dicotomia sujeito-objeto na compreensão dos fatos e obras humanos. Olhar a linguagem "de fora", considerar aspectos extralingüísticos de sua determinação, seria pretender um distanciamento metodológico que comprometeria a historicidade da compreensão. Aquilo que para concepções positivistas do fato humano constitui um vício e um obstáculo - o círculo lógico em que se vê a compreensão, uma vez que quem compreende está incluído no que quer compreender - para Gadamer, ao contrário, constitui a essência mesma do compreender. A coincidência entre conhecedor e conhecido é o que, desde Dilthey, é visto como a garantia de acesso do pensamento à experiência que excede a objetividade. É a totalidade vivida que, como pano de fundo, faz distinguir a forma particular do fenômeno humano, configurando o "círculo hermenêutico". Só a experiência de pertença em relação a tudo o que é humano permite compreender o fato ou a obra particulares, distinguir as experiências pretéritas e alheias das próprias, identificar, a um só tempo, o si mesmo e o Outro.

Mas se Dilthey ${ }^{11}$ buscava através dessa pertença chegar a conhecer objetivamente o Outro, seu horizonte histórico, Gadamer ${ }^{15}$, em sua recusa de distanciamento da linguagem, encara esse acesso ao Outro não como um resgate de seu horizonte e sim como uma "fusão de horizontes". Aquele que interpreta não decodifica uma experiência externa a si, a seu horizonte linguístico, mas decodifica a sua própria experiência a partir de necessidades e possibilidades trazidas pelo horizonte linguístico do Outro. Na hermenêutica de Gadamer o interpretado suscita questões inéditas para o 
intérprete, mas é o intérprete que possibilita ao interpretado a proposição dessas questões. Através desta complexa "dialética de pergunta e respos$t a{ }^{\prime \prime}$, sempre intermediada pela linguagem, realizase, segundo Gadamer, o compreender incessante com o qual a humanidade vai estatuindo e instaurando historicamente o seu mundo, reconstruindo continuamente o passado do futuro que enxerga desde cada presente.

\section{Considerações Finais}

Naturalmente diversas outras interlocuções teóricas relevantes poderiam ser chamadas a compor o mapeamento filosófico aqui realizado, o qual, porém, não se propunha a ser exaustivo. Entre elas, talvez seja útil mencionar, ao menos, dois nomes que apresentam afinidades muito estreitas com a perspectiva aqui privilegiada. Michel Foucault é um deles. Seus desenvolvimentos sobre a "episteme", como solo de possibilidades discursivas ${ }^{12,13}$, e sobre o substrato "microfísico" do exercício do poder ${ }^{14}$ podem trazer valiosas contribuições. Ricoeur ${ }^{32}$, com sua "arqueologia do sujeito" parece também ser interlocução indispensável.

Entre as contribuições examinadas, destaca-se o particular interesse dos elementos filosóficos que podem ser sinteticamente expressos como constitutivos de uma "atitude" críticohermenêutica, como as noções de "ação comunicativa", "caráter consensual da verdade", "dialética de pergunta-resposta" e "fusão de horizontes".

O especial interesse epistemológico desses constructos filosóficos reside na irresistível pulsão que exercem no sentido de resgatar a historicidade e intersubjetividade não só da ciência sobre a qual se os aplica, mas também da própria reflexão epistemologica. Esse traço parece fundamental para a superação de uma postura maniqueísta, muito negativa, embora freqüente, que faz confundir a crítica da ciência, esta atitude filosófica de recusa produtiva de "apriorismos", com a rejeição da totalidade do horizonte historicamente constituído pelo objeto da crítica. Essa confusão é comum entre aqueles que rejeitam a crítica, mas também, o que é pior, entre os que criticam.

A atitude hermenêutica obriga à reflexividade do próprio ato de interpretar, inibindo a substituição da alienação quanto ao significado do fato científico pela alienação quanto ao significado de sua crítica. Com efeito, interpretar os impasses da epidemiologia em termos do sentido que estes assumem em relação à "produção" de um espaço público da saúde livre e justo, não garante, como uma espécie de crédito automático, a liberdade e justiça dessa interpretação. Para tanto, será preciso ter sempre presente o quanto e como o sentido de que se investe qualquer crítica é devedor e credor do que se quer criticado. Será preciso, enfim, assumir, no plano da reflexão em si mesma, a comunidade de origem e destino do pensar/agir humano e recusar qualquer verdade no mundo que não seja imediatamente expressão da história que temos estado todos, o tempo todo, construindo.

\section{Agradecimento}

À Prof ${ }^{a} r^{2}$ Maria Odila Leite da Silva Dias, Prof titular do Dep. de História da Faculdade de Filosofia, Letras e Ciências Humanas da USP pelas esclarecedoras discussões acerca da história e da hermenêutica.

AYRES, J.R. de C. M. [Historical interpretation and scientific transformation: the hermeneutical task of a critical theory of epidemiology]. Rev. Saúde Pública, 28: $311-9$, 1994. The objective of this work is to discuss the scope of historical issues in an epistemological approach to epidemiology. Considering the contributions to a practical comprehension of science made by Habermas's theory of communicative action and Gadamer's philosophical hermeneutics, this study attempts to explore the sense in which a historical point of view redirects the main epistemological questions of epidemiology. In contrast to strictly formal approaches, a historically enhanced epistemology seems to be a more prolific source of reasoning about the striving of epidemiology for scientific axioms. The relevance of historical theoretical improvements to epistemological methods themselves, with regard to emancipatory ideals, is particularly emphasized.

Keywords: Epidemiology. History. Philosophy. Social Medicine.

\section{Referências Bibliográficas}

1. ADORNO, T.W. Introducción. In: Adorno, T.W. et al. La disputa del positivismo en la sociologia alemana. Barcelona, Ed. Grijalbo,1973. p. 11-80.

2. ALMEIDA FILHO, N. A epidemilogia e a clínica. Salvador, APCE-ABRASCO, 1992.

3. A YRES, J.R. de C.M. O problema do conhecimento verdadejro na epidemiologia. Rev. Saúde Pública, 26: 206-14, 1992.

4. AYRES, J.R. de C.M. Elementos historicos e filosóficos para a crítica da epidemiologia. Rev. Saúde Pública, 27: 135-44, 1993.

5. BERNSTEIN, R.J. Beyond objectivism and relativism: science, hermeneutics, and praxis. Philadelphia, University of Pennsylvania Press, 1985.

6. BLEICHER, J. Hermenêutica contemporânea. Lisboa, Ediçōes 70, 1992.

7. CANGUILHEM, G. Le vivant et son milieu. In: Canguilhem, G. La connaissance de la vie. Paris, Librairie Philosophique J. Vrin, 1985. p. 129-54. 
8. CANGUILHEM, G. O que é uma ideologia científica? In: Canguilhem, G. Ideologia.e racionalidade nas ciencias da vida. Lisboa, Ediçōes 70, 1977.p. 31-42.

9. CZERESNIA, D. Construção científica e renovaçāo teórica: um desafio para a epidemiologia. PHYSIS: Rev. Saúde Colet., 3:77-90, 1993.

10. DELEUZE, G. A filosofia crítica de Kant. Lisboa, Ediçōes $70,1987$.

11. DILTHEY, W. Introducción a las ciencias del espíritu. Madrid Alianza Editorial, 1980.

12. FOUCAULT, M. A arqueologia do saber. Rio de Janeiro, Ed. Forense-Universitária, 1987.

13. FOUCAULT, M. As palavras e as coisas: uma arqueologia das ciências humanas. São Paulo, Ed. Martins Fontes, 1990.

14. FOUCAULT, M. Microfisica do poder. Rio de Janeiro, Ed. Graal, 1984.

15. GADAMER, H-G. Verdad y metodo. Salamanca, Ed. Sígueme, 1991.

16. GRANGER, G-G. Por um conhecimento filosófico. Campinas, Ed. Papirus, 1989.

17. HABERMAS, J. Dialética e hermenêutica. Porto Alegre, Ed. L\&PM., 1987.

18. HABERMAS, J. Mudança estrutural da esfera pública. Rio de Janeiro, Ed. Tempo Brasileiro, 1984.

19. HABERMAS, J. O discurso filovífico da modernidade. Lisboa, Ed. D. Quixote, 1990.

20. HABERMAS, J. Pensamento pós-metajisito. Rio de Janeiro, Ed. Tempo Brasileiro, 1990.

21. HABERMAS, J. Trabalho e interação. In: Habermas, J. Técnica e ciência como ideologia. Lisboa, Ediçס̃es 70 , 1987. p. 11-43.

22. HEKMAN, S. J. Hermenêutica e sociologia do conhecimento. Lisboa, Edições 70, 1990.

23. KONDER, L. O futuro da filosofia da práxis. Rio de Janeiro, Ed. Paz e Terra, 1992.

24. KUHN, T. S. A estrutura das revoluções científicas. São Paulo, Ed. Perspectiva, 1989.

25. LILIENFELD, D. E. Definitions of epidemiology. Am. J. Epidemiol., 107:87-90, 1978.
26. MENDES GONÇALVES, R. B. Reflexōes sobre a articulação entre a investigação epidemiológica e a prática médica a propósito das doenças crônicas e degenerativas. In: Costa, D. C., org. Epidemiologia: teoria e objeto. São Paulo, Ed. Hucitec-ABRASCO, 1990. p. $36-86$

27. MIETTINEN, O. S. Theorethical epidemiology: principles of occurrence research in medicine. New York, John Wiley, 1985.

28. MINAYO, M. C. D. S. \& SANCHES, O. Quantitativo qualitativo: oposição ou complementaridade? Cad. SaúdePública, 9: 239-62, 1993.

29. PALMER, R. E. Hermenêutica. Lisboa, Ediçōes 70, 1989.

30. PIAGET, J. Les méthodes de l'épistémologie. In: Piaget, J. et al. Logique et connaissance scientifique. Paris, Gallimard, 1967. p. 62-132.

31. RICOEUR, P. Interpretação e ideologias. Rio de Janeiro, Ed. Francisco Alves, 1988.

32. RICOEUR, P. O si-mesmo como um outro. Campinas, Ed. Papirus, 1991.

33. RUNES, D. D. ed. Diccionario de filosofia. Barcelona, Ed. Grijalbo, 1985.

34. SCHRAMM, R. F. \& CASTIEL, L. D. Processo saúdel doença e complexidade em epidemiologia. Cad. Saúde Pública, 8:379-90, 1992.

35. SNOW, J. Sobre a maneira de transmissão do cólera. São Paulo, Ed. Hucitec-ABRASCO, 1990.

36. STEIN, E. Dialética e hermenêutica, uma controvérsia sobre método em filosofia. In: Habermas, J. Dialética $e$ hermeneutica. Porto Alegre, Ed. L\&PM, 1987. p. 98-134.

37. TEIXEIRA, R. R. Epidemia e cultura: AIDS e o mundo securitário São Paulo, 1993. [Dissertação de Mestrado. Faculdade de Medicina da USP].

38. WHITEHEAD, A. N. A ciência e o mundo moderno. São Paulo, Ed, Brasiliense, 1951.

Recebido para publicaşão em 10.11.1993

Reapresentado em 13.4.1994

Aprovado para publicaçāo em 2.5 .1994 